\title{
Control of Molecular Weight Distribution in Polycondensation Polymers. Polyamide Synthesis
}

\author{
Yuji ShibASAKI, Tomoko ARAKI, Masaki OKAZAKI, \\ and Mitsuru UEDA ${ }^{\dagger}$ \\ Department of Organic and Polymeric Materials, Graduate School of Science and Engineering, Tokyo Institute \\ of Technology, 2-12-1 O-okayama, Meguro-ku, Tokyo 152-8552, Japan
}

(Received October 19, 2001; Accepted February 26, 2002)

\begin{abstract}
Synthesis of the aromatic polyamide with a narrow molecular weight distribution $\left(M_{\mathrm{w}} / M_{\mathrm{n}}\right)$ was investigated via polycondensation. The new monomers, metal amide anions of 4-( $N$-octylamino)benzoylbenzoxazolin-2-thione (2) was prepared to prevent conventional polycondensation. The number average molecular weights $\left(M_{\mathrm{n}}\right) \mathrm{s}$ of the resulting polymer could be controlled varying the feed ratio of $\mathbf{2}$ and $p$-nitrobenzoyl chloride in the range of $10^{3}-10^{4}$ maintaining narrow $M_{\mathrm{w}} / M_{\mathrm{n}} \mathrm{s}(\sim 1.15)$. The kinetic plots of the polymerization gave a linear relationship between polymerization time and $-\left(1 /[I]_{0}\right) \ln \left([M] /[M]_{0}\right)$, and the rate of the polymerization was estimated as $116.4 \mathrm{~mol}^{-1} \mathrm{~h}^{-1}$.

KEY WORDS Controlled Polymerization / Polycondensation / Aromatic Polyamide / LiCl /

Grignard Reagent / Low Polydispersity / Condensative Chain Polymerization /
\end{abstract}

Controlled and living polymerizations allow the synthetic approach of well-defined polymers with controlled molecular weights $\left(M_{\mathrm{n}}\right)$, molecular weight distributions $\left(M_{\mathrm{w}} / M_{\mathrm{n}}\right)$, and terminal functionalities. ${ }^{1}$ It has been realized in polymerizations of numerous molecules via anionic, ${ }^{2}$ cationic, ${ }^{3}$ radical, ${ }^{4}$ coordination, ${ }^{5}$ and group transfer systems. ${ }^{6}$ However, most of these have strict limitations on the monomer structures for stabilization of propagating species in order to avoid side reactions such as termination and chain transfer. On the other hands, in step-growth polymerization, which generally possesses polymers having functionalities in their backbone, $M_{\mathrm{n}}$ as well as $M_{\mathrm{w}} / M_{\mathrm{n}}$ is somewhat difficult to control due to the statistical nature in its mechanism; the initiation, propagation, and termination reactions are essentially identical. Basic principle in polycondensation is that stoichiometric imbalance in monomer feed ratio decreases the degree of the polymerization, and that the polymerization should obey the Carothers equation to yield polymers with infinity at $100 \%$ conversion under ideal conditions. Thus, the $M_{\mathrm{n}}$ and $M_{\mathrm{w}} / M_{\mathrm{n}}$ control in stepgrowth polymerization is one of the most attractive subjects in polymer chemistry. Lenz et al. reported that the $M_{\mathrm{n}}$ s of the poly(phenylene sulfide)s obtained by the aromatic nucleophilic substitutions of alkali metal 4-halothiophenoxides are higher than those predicted by the Carothers equation probably because of the different reactivity between the thiophenoxides in the monomers and those in the polymer chain ends. ${ }^{7}$ Poly( $p$-phenylene sulfone) was synthesized by the self-condensation of sodium 4-halobenzenesulfonate,

${ }^{\dagger}$ To whom all correspondence should be addressed. where the addition of a small amount of 4-fluorophenyl sulfone greatly increases the yield of the resulting polymer, presumably by acting as an initiator for a chaintype polymerization. ${ }^{8}$ The phase transfer catalyzed oxidative polymerization of 4-bromo-2,6-dimethylphenol in the presence of 2,4,6-trimethylphenol or 4-tert-butyl2,6-dimethylphenol was investigated to control $M_{\mathrm{n}}$ and $M_{\mathrm{w}} / M_{\mathrm{n}} \cdot{ }^{9}$ Although the $M_{\mathrm{n}} \mathrm{s}$ of the resulting polymers increased with the feed ratio of the monomer and initiator, those were different from calculated values. The phase transfer catalyzed polymerization of 4-bromomethyl-2- $n$-octyloxybenzoate was also investigated by Yokozawa et al. ${ }^{10}$ The $M_{\mathrm{n}}$ of the resulting polyester was controlled up to 4000 with less than 1.3 of $M_{\mathrm{w}} / M_{\mathrm{n}}$. The first critical synthesis of a polymer with controlled $M_{n}(\sim 20000)$ and $M_{\mathrm{w}} / M_{\mathrm{n}}(\sim 1.1)$ was achieved in the polyamide synthesis using 4- $(N-$ octylamino)benzoic acid phenylester. ${ }^{11}$ They also reported the synthesis of the aromatic polyethers with low $M_{\mathrm{w}} / M_{\mathrm{n}}$ values $(\sim 1.1)$, but the attainable $M_{\mathrm{n}}$ was less than 5000 because of the poor solubility of resulting polymers. ${ }^{12}$ Although their method for polyamide synthesis provide the higher level control of $M_{\mathrm{n}}$ and $M_{\mathrm{W}} / M_{\mathrm{n}}$ in polycondensation than the others, it requires complicated process with peculiar reagents such as $N$ triethylsilyl- $N$-octylaminobenzene and $\mathrm{CsF}$ as a base to generate "monomer", and excess amounts of 18-crown6-ether as solubilizing agent for CsF. Ensure the concept for the chain-growth polycondensation of various monomers, the polymerization method must be simplify enough to be applicable in various monomers. We here describe a new synthetic method to obtain a polyamide with controlled $M_{\mathrm{n}}$ and $M_{\mathrm{w}} / M_{\mathrm{n}}$ in polycon- 
densation process using conventional bases.

\section{EXPERIMENTAL}

\section{Materials}

Tetrahydrofuran (THF) was dried over sodium and distilled before use under nitrogen. $\mathrm{NaH}$ was washed with hexane twice, and used under nitrogen atmosphere. Organo lithium and Grignard reagents were used as received. Diphenyl(2,3-dihydro-2-thioxo-3benzoxazolyl)phosphonate (DBOP) was prepared according to the literature. ${ }^{13} 4$-( $N$-Octylamino)benzoic acid was prepared according to the literature. ${ }^{14}$ Lithium chloride was dried at $180^{\circ} \mathrm{C}$ for $2 \mathrm{~h}$ under reduced pressure. All other reagents and solvents were used without further purification.

\section{Measurements}

FT-IR spectra were measured on a Horiba FT-720 spectrometer. ${ }^{1} \mathrm{H}$ and ${ }^{13} \mathrm{C}$ NMR spectra were recorded with a Bruker DPX300S spectrometer. Number- and weight-average molecular weights $\left(M_{\mathrm{n}}\right.$ and $\left.M_{\mathrm{w}}\right)$ were measured by gel permeation chromatography (GPC) on a Jasco GULLIVER 1500 system equipped with a polystyrene gel column (Plgel $5 \mu \mathrm{m}$ MIXED-C) eluted with $\mathrm{CHCl}_{3}$ at a flow rate of $1.0 \mathrm{~mL} \mathrm{~min}^{-1}$ calibrated by standard polystyrene samples. Preparative high pressure liquid chromatography (HPLC) was performed with a Japan Analytical Industry LC-908 equipped with two consecutive gel columns, JAIGELs $1 \mathrm{H}$ and $2 \mathrm{H}$, detected with refractive index and ultraviolet at $254 \mathrm{~nm}$ using chloroform as an eluent with a flow rate of $3.8 \mathrm{~mL} \mathrm{~min}^{-1}$.

Synthesis of 4-(N-octylamino)benzoylbenzoxazolin-2thione (1)

To a solution of 4-( $N$-octylamino)benzoic acid $(10 \mathrm{~g}$, $40.1 \mathrm{mmol})$ and triethylamine $(5.9 \mathrm{~mL}, 42 \mathrm{mmol})$ in NMP $(26 \mathrm{~mL})$ was added DBOP $(18.6 \mathrm{~g}, 48.6 \mathrm{mmol})$ at $25^{\circ} \mathrm{C}$. The mixture was stirred at the temperature for $30 \mathrm{~min}$, then at $50^{\circ} \mathrm{C}$ for $2 \mathrm{~h}$. The resulting solution was poured into $100 \mathrm{~mL}$ of $3 \mathrm{wt} \%$ aqueous $\mathrm{NaHCO}_{3}$ solution, filtered, washed with $\mathrm{H}_{2} \mathrm{O}$ several times, dissolved in $\mathrm{CH}_{2} \mathrm{Cl}_{2}$, dried over $\mathrm{MgSO}_{4}$, and filtered. The filtrate was concentrated under reduced pressure, and the residue was recrystalized from methanol, then ethyl acetate/hexane (1/1 in volume ratio) to obtain yellow curdy $(57 \%$ yield). IR $(\mathrm{KBr}) \vee 3378(\mathrm{~N}-\mathrm{H}), 2915$ (C-H aromatic), 2853 (C-H aliphatic), $1662 \mathrm{~cm}^{-1}$ (active amide). ${ }^{1} \mathrm{H}$ NMR $\left(\mathrm{CDCl}_{3}, 25^{\circ} \mathrm{C}\right) \delta 0.89(\mathrm{t}, 3 \mathrm{H}$, $\left.\mathrm{CH}_{3}\right), 1.18-1.52\left(\mathrm{~m}, 10 \mathrm{H}, \mathrm{CH}_{2}\right), 1.60-1.70(\mathrm{~m}, 2 \mathrm{H}$, $\left.\mathrm{CH}_{2}\right), 3.20$ (q, $\left.2 \mathrm{H}, \mathrm{CH}_{2}\right), 4.62$ (b, $1 \mathrm{H}$, amide), $6.56(\mathrm{~d}$, $2 \mathrm{H}$, aromatic), 7.16-7.41 (m, $4 \mathrm{H}$, aromatic), $7.78(\mathrm{~d}$,
$2 \mathrm{H}$, aromatic); ${ }^{13} \mathrm{C} \mathrm{NMR}\left(\mathrm{CDCl}_{3}, 25^{\circ} \mathrm{C}\right) \delta 14.2\left(\mathrm{CH}_{3}\right)$, 22.8, 27.3, 29.4, 29.5, 32.0, $43.6\left(\mathrm{CH}_{2}\right), 110.4,112.0$, $112.1,118.2,125.0,125.3,132.0,134.6,147.9,154,7$ (aromatic), 165.6 (C=O), 179.4 (C=S); Elemental Anal. Calcd for $\mathrm{C}_{22} \mathrm{H}_{26} \mathrm{~N}_{2} \mathrm{O}_{2} \mathrm{~S}$ : C; 69.02, $\mathrm{H} ; 6.85, \mathrm{~N} ; 7.32, \mathrm{~S}$; 8.38. Found: C; 68.58, H; 6.33, N; 7.04, S; 7.97.

\section{Polymerization}

All polymerization reactions were carried out with the following general procedure: All glass vessels were heated in vacuo before use, filled with and handled in a stream of dry nitrogen. Into a flask equipped with a three way stop-cock, $1.45 \mathrm{~g}(3.79 \mathrm{mmol})$ of $1,2.40 \mathrm{~g}$ (56.9 mmol) of $\mathrm{LiCl}$, and $25 \mathrm{~mL}$ of THF were placed under nitrogen. The solution was cooled to $-40^{\circ} \mathrm{C}$, and then $5.68 \mathrm{~mL}(5.68 \mathrm{mmol})$ of EtMgBr solution in THF was slowly added to give light yellow monomer solution. After $30 \mathrm{~min}$ at the temperature, $0.0353 \mathrm{mg}$ $(0.190 \mathrm{mmol})$ of $p$-nitrobenzoyl chloride was charged to start the polymerization. The light yellow reaction solution was kept stirring at the temperature for another $24 \mathrm{~h}$, and then quenched with $p$-toluidine. The resulting mixture was poured into $100 \mathrm{~mL}$ of $3 \mathrm{wt} \%$ aqueous $\mathrm{NaHCO}_{3}$ solution, filtered, washed with $\mathrm{H}_{2} \mathrm{O}$ several times, dissolved in $\mathrm{CH}_{2} \mathrm{Cl}_{2}$, dried over $\mathrm{MgSO}_{4}$, and filtered. The filtrate was concentrated under reduced pressure to give a brawn viscous solid. It was purified by a preparative HPLC providing colorless viscous in $93 \%$ yield. IR ( $\mathrm{KBr}) \vee 2923$ (C-H aromatic), 2854 (C$\mathrm{H}$ aliphatic), $1650 \mathrm{~cm}^{-1}$ (amide). ${ }^{1} \mathrm{H}$ NMR $\left(\mathrm{CDCl}_{3}\right) \delta$ $0.87\left(\mathrm{t}, 3 \mathrm{H}, \mathrm{CH}_{3}\right), 1.16-1.38\left(\mathrm{~m}, 10 \mathrm{H}, \mathrm{CH}_{2}\right), 1.42-1.68$ $\left(\mathrm{m}, 2 \mathrm{H}, \mathrm{CH}_{2}\right), 2.32\left(\mathrm{~s}\right.$, terminal $\left.\mathrm{CH}_{3}\right), 3.72-4.00(\mathrm{~m}$, $\left.2 \mathrm{H}, \mathrm{CH}_{2}\right), 6.70-6.88$ (d, 2H, aromatic), 6.99-7.16 (d, $2 \mathrm{H}$, aromatic), 7.52 (d, terminal aromatic), 7.81 (d, terminal aromatic), 7.97 (d, terminal aromatic); ${ }^{13} \mathrm{C}$ NMR $\left(\mathrm{CDCl}_{3}, 25^{\circ} \mathrm{C}\right) \delta 14.2\left(\mathrm{CH}_{3}\right), 22.7,27.1,28.0,29.4$, 29.5, 32.0, $50.7\left(\mathrm{CH}_{2}\right), 126.9,129.7,134.6,144.8$, (aromatic), 169.0 (amide); Elemental Anal. Calcd for $\left(\mathrm{C}_{15} \mathrm{H}_{21} \mathrm{NO}\right)_{\mathrm{n}}$ : $\mathrm{C} ; 72.94, \mathrm{H} ; 8.78, \mathrm{~N} ; 6.02$. Found: $\mathrm{C}$; 72.77, H; 8.42, N; 6.22 .

\section{Reaction of p-Nitrobenzoyl Chloride with 1}

Into a flask equipped with a three way stop-cock, $0.3825 \mathrm{~g}(1.0 \mathrm{mmol})$ of $1,0.6360 \mathrm{~g}(15 \mathrm{mmol})$ of $\mathrm{LiCl}$, and $4.5 \mathrm{~mL}$ of THF were placed under nitrogen. The yellow solution was cooled to $-40^{\circ} \mathrm{C}$, and then $1.1 \mathrm{~mL}$ $(1.1 \mathrm{mmol})$ of EtMgBr solution in THF was slowly added through a syringe. After $30 \mathrm{~min}$ at the temperature, $0.1856 \mathrm{~g}(1.0 \mathrm{mmol})$ of $p$-nitrobenzoyl chloride was charged, and the resulting red colored solution was kept stirring for another $30 \mathrm{~min}$. Then $0.1072 \mathrm{~g}$ $(1.0 \mathrm{mmol})$ of $p$-toluidine was added into the reaction mixture, and the solution was gradually warmed to 
$25^{\circ} \mathrm{C}$ for $30 \mathrm{~min}$. The resulting solution was poured into $100 \mathrm{~mL}$ of $3 \mathrm{wt} \%$ aqueous $\mathrm{K}_{2} \mathrm{CO}_{3}$ solution, filtered, washed with $3 \mathrm{wt} \%$ of $\mathrm{HCl}$ in $\mathrm{H}_{2} \mathrm{O}, \mathrm{H}_{2} \mathrm{O}$ several times, dissolved in $\mathrm{CH}_{2} \mathrm{Cl}_{2}$, dried over $\mathrm{MgSO}_{4}$, and filtered. The filtrate was concentrated under reduced pressure to give a brawn solid. This was purified by silica gel column chromatography (hexane/ethyl acetate $=2 / 1$ in volume ratio; $92 \%$ yield) $(3) . \mathrm{Mp}=60-62^{\circ} \mathrm{C}$. IR (KBr) $v 3428$ (N-H amide), 2927 (C-H aromatic), 2854 (C-H aliphatic), 1650, 1600 (amide), $1515 \mathrm{~cm}^{-1}$ $\left(\mathrm{NO}_{2}\right) .{ }^{1} \mathrm{H} \mathrm{NMR}\left(\mathrm{CDCl}_{3}\right) \delta 0.87\left(\mathrm{t}, 3 \mathrm{H}, \mathrm{CH}_{3}\right), 1.16-$ $1.42\left(\mathrm{~m}, 10 \mathrm{H}, \mathrm{CH}_{2}\right), 1.57-1.71\left(\mathrm{~m}, 2 \mathrm{H}, \mathrm{CH}_{2}\right), 2.32$ (s, $\left.3 \mathrm{H}, \mathrm{CH}_{3}\right), 3.94\left(\mathrm{t}, 2 \mathrm{H}, \mathrm{CH}_{2}\right), 7.12$ (t, $4 \mathrm{H}$, aromatic), 7.45 (q, 4H, aromatic), 7.57 (b, 1H, amide) $7.75(\mathrm{~d}, 2 \mathrm{H}$, aromatic), $8.02\left(\mathrm{~d}, 2 \mathrm{H}\right.$, aromatic); ${ }^{13} \mathrm{C} \mathrm{NMR}\left(\mathrm{CDCl}_{3}\right.$, $\left.25^{\circ} \mathrm{C}\right) \delta 14.3,21.1\left(\mathrm{CH}_{3}\right), 22.9,27.3,28.2,29.4,29.5$, $32.1,50.9\left(\mathrm{CH}_{2}\right), 121.0,123.5,125.8,128.1,129.8$, $129.9,134.3,134.9,135.6,142.6,145.9,148.7$ (aromatic), 164.7, 168.0 (amide); Elemental Anal. Calcd for $\mathrm{C}_{29} \mathrm{H}_{33} \mathrm{~N}_{3} \mathrm{O}_{4}$ : C; 71.44, $\mathrm{H} ; 6.82, \mathrm{~N} ; 8.62$. Found: C; 71.79, H; 7.19, N; 8.50.

\section{Kinetic Study}

The kinetic study for the polymerization of $\mathbf{2}$ generated by the reaction of $\mathbf{1}$ with $\mathrm{EtMgBr}$ in the presence of $\mathrm{LiCl}$ was carried out in THF at $-40^{\circ} \mathrm{C}$. The monomer concentration $[M]$ on time $t$ was estimated by the integration ratios of signals at 7.8 and $6.8 \mathrm{ppm}$ corresponding to aromatic protons of monomer and polymer, respectively, in ${ }^{1} \mathrm{H}$ NMR spectra.

\section{RESULTS AND DISCUSSION}

\section{Monomer Synthesis}

For investigation of condensative chain polymerization, we first prepared 4-( $N$-octylamino)benzoylbenzoxazolin-2-thione (1) as a monomer precursor in order to endow adequate solubility ${ }^{11}$ both to monomer and resulting polymer (Scheme 1). The selective formation of the active amide 1 was confirmed by IR, ${ }^{1} \mathrm{H}$, and ${ }^{13} \mathrm{C}$ NMR spectroscopies. Monomers 2 were then prepared from the reaction of $\mathbf{1}$ with commercially available bases such as $\mathrm{NaH}, n$-BuLi, EtMgCl, EtMgBr, and $s e c-\mathrm{BuMgBr}$.

\section{Polymerization}

Table I summarizes the results of the polymerization of monomers 2 initiated by $p$-nitrobenzoyl chloride ( $1 / 20$ equiv to the monomer) in THF at $-40^{\circ} \mathrm{C}$ for $3 \mathrm{~h}$ in the presence and absence of $\mathrm{LiCl}$ as an additive (Scheme 2). Using $\mathrm{NaH}$ as a base, the solution of $\mathbf{2}$ became heterogeneous, and its conversion into the polymer was very low even in the presence of $\mathrm{LiCl}$

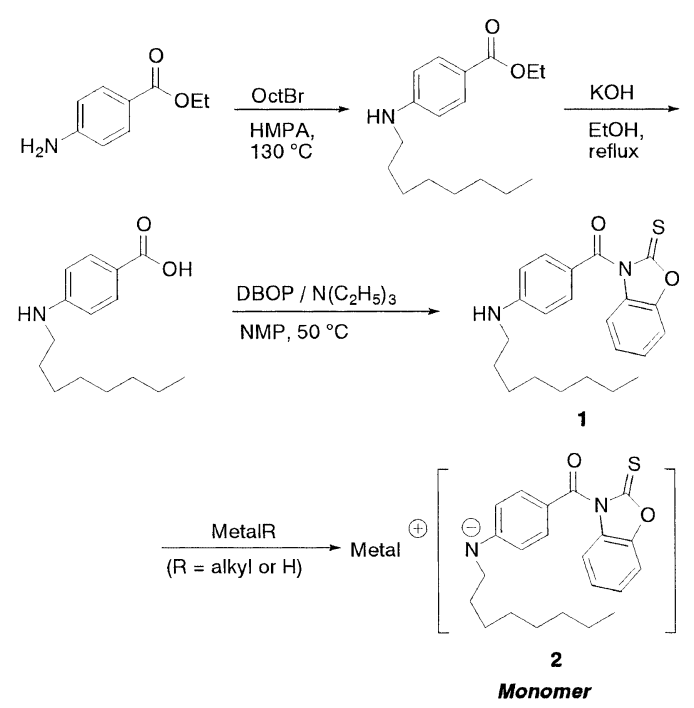

Scheme 1.

Table I. Synthesis of Polyamide with Several Bases ${ }^{\mathrm{a}}$

\begin{tabular}{|c|c|c|c|c|}
\hline Run & Base & $\frac{\text { Conv }^{b}}{\%}$ & $M_{\mathrm{n}}^{\mathrm{c}}$ & $M_{\mathrm{w}} / M_{\mathrm{n}}^{\mathrm{c}}$ \\
\hline 1 & $\mathrm{NaH}$ & 2 & $\bar{d}$ & $d$ \\
\hline 2 & $\mathrm{NaH}+\mathrm{LiCl}$ & 4 & $d$ & $d$ \\
\hline 3 & $n$-BuLi & 45 & 1200 & 1.37 \\
\hline 4 & $n-\mathrm{BuLi}+\mathrm{LiCl}$ & 42 & 5100 & 1.60 \\
\hline 5 & $\mathrm{EtMgBr}$ & 10 & 400 & 1.37 \\
\hline 6 & $\mathrm{EtMgBr}+\mathrm{LiCl}$ & 91 & 6800 & 1.19 \\
\hline 7 & $\mathrm{EtMgCl}+\mathrm{LiCl}$ & 38 & 4800 & 1.20 \\
\hline 8 & $s e c-\mathrm{BuMgBr}+\mathrm{LiCl}$ & 40 & 3900 & 1.20 \\
\hline
\end{tabular}

${ }^{\mathrm{a} C o n d i t i o n s ;}[M]_{0}=0.15 \mathrm{M},[M]_{0} /[I]_{0}=20,[\mathrm{LiCl}]_{0} /[M]_{0}=$ 15 , $[\text { Base }]_{0} /[M]_{0}=1.5$, in THF at $-40^{\circ} \mathrm{C}$ for $3 \mathrm{~h}$. ${ }^{\mathrm{b}}$ Determined by ${ }^{1} \mathrm{H}$ NMR. ${ }^{c}$ Determined by GPC $\left(\mathrm{CHCl}_{3}\right.$, PSt standard $) .{ }^{\mathrm{d}}$ Not determined.

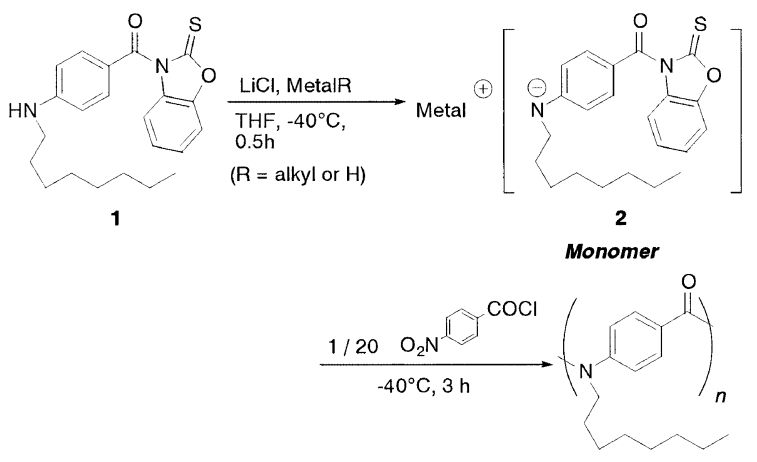

Scheme 2.

(runs 1 and 2). Monomer 2 generated with $n$-BuLi was converted to the polymer about $45 \%$, though the $M_{\mathrm{w}} / M_{\mathrm{n}}$ values were very high mainly because of the self-condensation of 2 (runs 3 and 4). Then, the Grignard reagents were employed as bases (runs 5-8). Although the monomer 2 generated with $\mathrm{EtMgBr}$ could not be polymerized efficiently (run 5), in conjunction with $\mathrm{LiCl}$ the polymerization proceeded smoothly to give the corresponding polyamide with a narrow $M_{\mathrm{w}} / M_{\mathrm{n}}(=1.19)$ in high conversion (run 6). Instead 
Table II. Synthesis of Polyamede

\begin{tabular}{|c|c|c|c|c|c|}
\hline Run & {$[\mathrm{LiCl}]_{0} /[M]_{0}$} & $\frac{\text { Temp }}{{ }^{\circ} \mathrm{C}}$ & $\frac{\text { Conb }^{b}}{\%}$ & $M_{\mathrm{n}}{ }^{\mathrm{c}}$ & $M_{\mathrm{w}} / M_{\mathrm{n}}^{\mathrm{c}}$ \\
\hline 1 & 0 & 25 & 2 & $\bar{d}$ & $d$ \\
\hline 2 & 5 & 25 & 45 & 3090 & 2.06 \\
\hline 3 & 15 & 25 & 37 & 6120 & 1.54 \\
\hline 4 & 15 & 0 & 34 & 14420 & 1.44 \\
\hline 5 & 15 & -40 & 91 & 6800 & 1.18 \\
\hline 6 & 15 & -78 & 3 & $d$ & $d$ \\
\hline 7 & $15\left(\mathrm{MgCl}_{2}\right)$ & -40 & 2 & $d$ & $d$ \\
\hline \multicolumn{6}{|c|}{$\begin{array}{l}{ }^{\mathrm{a}} \text { Conditions; }[M]_{0}=0.15 \mathrm{M},[M]_{0} /[I]_{0}=20,[\mathrm{LiCl}]_{0} /[M]_{0}= \\
-15,[\mathrm{EtMgBr}]_{0} /[M]_{0}=1.5 \text {, in THF for } 3 \mathrm{~h} .{ }^{\mathrm{b}} \text { Determined by } \\
\text { H NMR. }{ }^{\mathrm{c}} \text { Determined by GPC }\left(\mathrm{CHCl}_{3} \text {, PSt standard). }{ }^{\mathrm{d}} \text { No }\right. \\
\text { etermined. }\end{array}$} \\
\hline
\end{tabular}

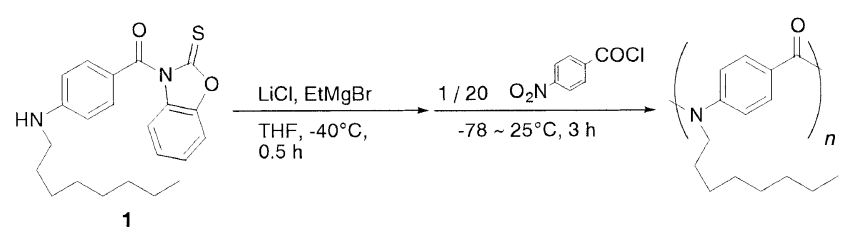

Scheme 3.

of $\mathrm{EtMgBr}, \mathrm{EtMgCl}$ was employed to generate 2 for the chain-growth polymerization. Although the selfcondensation could be avoided in THF at $-40^{\circ} \mathrm{C}$ for $3 \mathrm{~h}$ without the addition of the initiator, the rate of the polymerization was very low (run 7). Such a slow propagation was observed as well, when the polymerization was conducted using 2 generated with $s e c-\mathrm{BuMgBr}$ in the presence of $\mathrm{LiCl}$ (run 8). Therefore, $\mathrm{EtMgBr}$ in conjunction with $\mathrm{LiCl}$ was selected to generate 2 for study of condensative chain-polymerization.

Table II summarizes the results of the polymerization of 2 generated with EtMgBr initiated by $p$-nitrobenzoyl chloride (1/20 equiv to 2$)$ in THF at various temperatures for $3 \mathrm{~h}$ in the presence and absence of $\mathrm{LiCl}$ (Scheme 3). In the absence of $\mathrm{LiCl}$, no polymer was obtained at $25^{\circ} \mathrm{C}$ (run 1). Increasing the amounts of $\mathrm{LiCl}$, conversions of $\mathbf{2}$ increased up to about $40 \%$, and $M_{\mathrm{w}} / M_{\mathrm{n}}$ values became smaller (runs 1-3). In order to achieve higher control of the polymerization, the reaction temperature was varied from 25 to $-78^{\circ} \mathrm{C}$. The corresponding polyamide with a narrow $M_{\mathrm{w}} / M_{\mathrm{n}}$ was obtained in $91 \%$ conversion at $-40^{\circ} \mathrm{C}$. At much lower temperature $\left(-78^{\circ} \mathrm{C}\right)$ or using $\mathrm{MgCl}_{2}$ instead of $\mathrm{LiCl}$ as an additive, the polymerization hardly proceeded probably because of its insufficient reactivity of $\mathbf{2}$ or insolubility of $\mathrm{MgCl}_{2}$ in THF, respectively (runs 6 and 7).

\section{Investigation of Monomer Stability}

To clarify the stability of $\mathbf{2}$ derived from 1, its solution in THF was hold at $-40^{\circ} \mathrm{C}$ in the presence of $\mathrm{LiCl}$ for $30 \mathrm{~min}$. It was then quenched with $\mathrm{H}_{2} \mathrm{O}$, and extracted from ether. The active amide $\mathbf{1}$ was quantita-

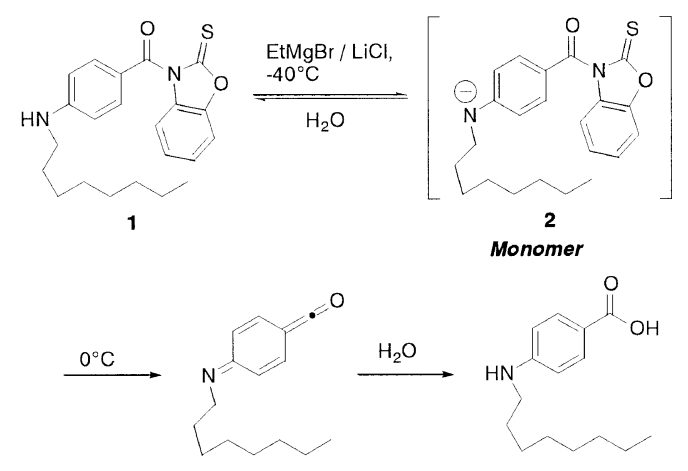

Scheme 4.
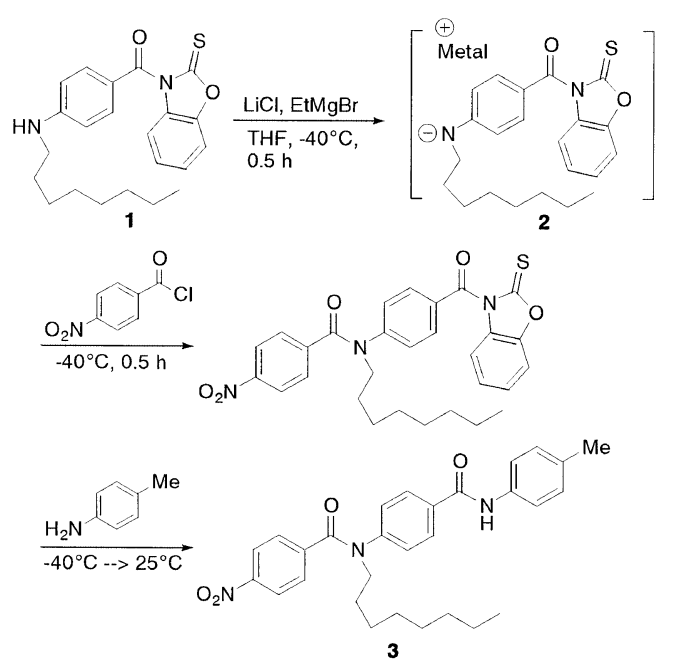

Scheme 5.

tively recovered, confirmed by ${ }^{1} \mathrm{H}$ NMR spectroscopy. On the contrary, only $16 \%$ of 1 was recovered when the THF solution of $\mathbf{2}$ was kept at $0^{\circ} \mathrm{C}$ in the presence of $\mathrm{LiCl}$ for $30 \mathrm{~min}$. The other products were $39 \%$ of 4 -( $N$-octylamino)benzoic acid and $45 \%$ of oligomers. These indicated that in-situ generated monomer 2 were stable below $-40^{\circ} \mathrm{C}$, and if the temperature was raised up to $0^{\circ} \mathrm{C}, \mathbf{2}$ was converted to carboxylic acid probably through a ketene derivative (Scheme 4).

Since the monomer 2 solution in THF was found to be stable at $-40^{\circ} \mathrm{C}$ in the presence of $\mathrm{LiCl}$, then the equimolar reaction of $\mathbf{2}$ with $p$-nitrobenzoyl chloride, followed by quenching with $p$-toluidine was investigated as a model reaction in the polymerization (Scheme 5). The final product 3 was isolated by silica gel column chromathography, and characterized by ${ }^{1} \mathrm{H},{ }^{13} \mathrm{C}$ NMR, IR, and elemental analyses. In the ${ }^{1} \mathrm{H}$ NMR spectrum, in addition to signals due to 1 unit of $a-d, h$, and $i$ at $0.87,1.16-1.42,1.57-1.71,3.95$, 7.12 , and $7.75 \mathrm{ppm}$, respectively, signals assignable to end groups $(e-g, j$, and $k)$ were observed at $2.32,7.45$, $7.12,7.45$, and $8.02 \mathrm{ppm}$, respectively (Figure 1). The yield of 3 was estimated as $92 \%$, indicating that the initiation and termination of the polymerization might be occurred without any side reactions. 

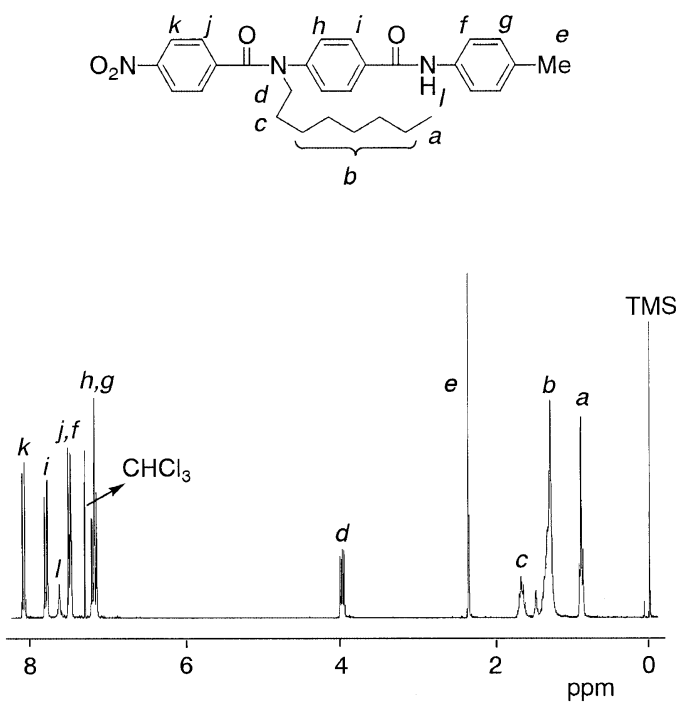

Figure 1. ${ }^{1} \mathrm{H}$ NMR spectrum $\left(300 \mathrm{MHz}, \mathrm{CDCl}_{3}\right)$ of the model compound obtained by the reaction of 4-nitrobenzoic acid chloride with 1 in the presence of $\mathrm{LiCl}$ and $\mathrm{EtMgBr}$, followed by the reaction with $p$-toluidine in THF.

Table III. Synthesis of Polyamede ${ }^{\mathrm{a}}$

\begin{tabular}{|c|c|c|c|c|c|}
\hline Run & {$[M]_{0} /[I]_{0}$} & $\frac{\text { Conv }^{b}}{\%}$ & $\frac{M_{\mathrm{n}}}{\mathrm{calc}}$ & $\frac{M_{\mathrm{n}}^{\mathrm{b}}}{\mathrm{NMR}}$ & $M_{w} / M_{\mathrm{n}}^{\mathrm{c}}$ \\
\hline 1 & 20 & 99 & 4800 & 4700 & 1.15 \\
\hline 2 & 40 & 98 & 9300 & 9100 & 1.13 \\
\hline 3 & 50 & 99 & 11700 & 10900 & 1.15 \\
\hline 4 & 100 & 91 & 21300 & 20100 & 1.17 \\
\hline
\end{tabular}

\section{Polymerization of Metal Amide 2 in the Presence of $\mathrm{LiCl}$}

Table III summarizes the results of the polymerization of 2 generated with $\mathrm{EtMgBr}$ changing the feed ratio of 2 and initiator. The polymers with narrow $M_{\mathrm{w}} / M_{\mathrm{n}} \mathrm{s}$ (1.13-1.17) were obtained quantitatively, where the $M_{\mathrm{n}} \mathrm{s}$ determined from the integration ratio in ${ }^{1} \mathrm{H}$ NMR could be tailored by varying the feed ratio and the values showed good agreement with theoretical ones (runs $1-4)$.

Figure 2 shows the kinetic plots of the polymerization obtained in run 1 in Table III based on a first order equation as follows.

$-\mathrm{d}[M] / \mathrm{d} t=k\left[P^{*}\right][M]\left(P^{*} ;\right.$ polymer propagating end)

$-[I]_{0}^{-1} \ln \left\{[M] /[M]_{0}\right\}=k t$ (I; initiator, $[M]_{0}$; initial monomer concentration)

The kinetic plots of the polymerization gave a linear relationship between polymerization time and $-\left(1 /[I]_{0}\right) \ln \left([M] /[M]_{0}\right)$. This indicated that the polymerization of 1 should proceed via chain growth manner without termination like monomer transformation reaction described in Scheme 4. The rate constant of

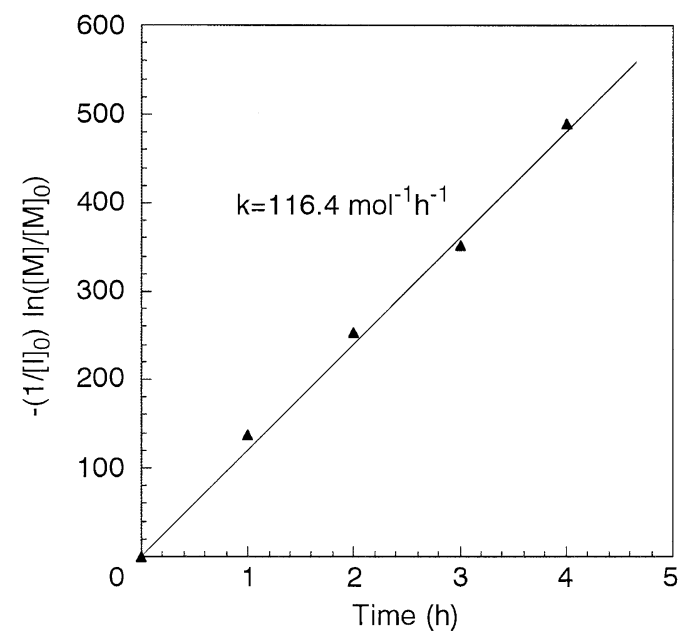

Figure 2. Relationships between time and $-\left(1 /\left[I_{0}\right) \times\right.$ $\ln \left([M] /[M]_{0}\right)$ in the polymerization obtained in run 1 in Table III based on a first order equation.

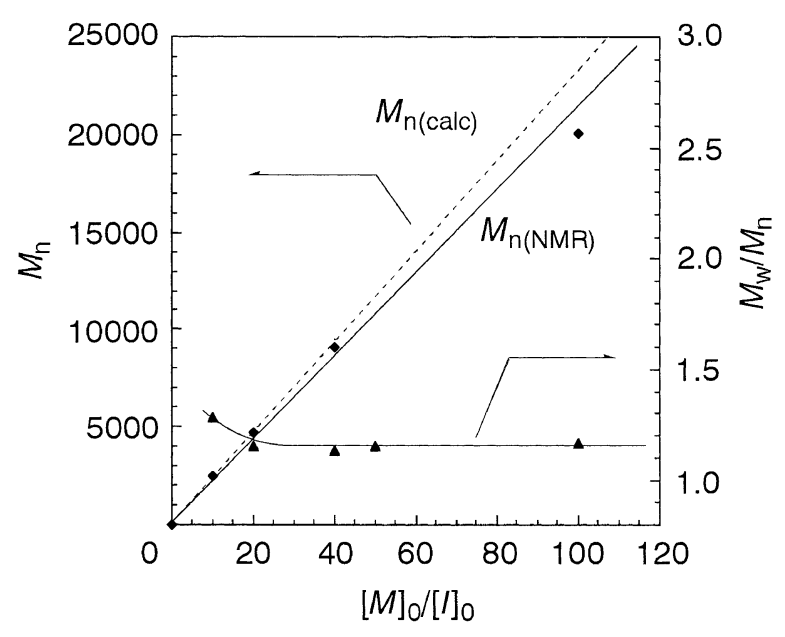

Figure 3. Dependence of $M_{\mathrm{n}}$ and $M_{\mathrm{w}} / M_{\mathrm{n}}$ of the resulting polyamide on $[M]_{0} /[I]_{0}$. A broken line showed the theoretical value, $M_{\text {n(calc) }}$ calculated by the feed ratio of the monomer to initiator, and a solid line with $\bullet$ did the measured value $M_{\mathrm{n} \text { (NMR) }}$ by ${ }^{1} \mathrm{H}$ NMR.

the polymerization was determined as $116.4 \mathrm{~mol}^{-1} \mathrm{~h}^{-1}$.

Figure 3 shows the dependence of the $M_{\mathrm{n}}$ on $[M]_{0} /[I]_{0}$ ratio obtained in the polymerization of Table III. The $M_{\mathrm{n}}$ increased linearly with the feed ratio of monomer and initiator maintaining narrow $M_{\mathrm{w}} / M_{\mathrm{n}} \mathrm{s}$. Thus, the polycondensation in this system proceeded via chain growth manner.

Figure 4 illustrates the ${ }^{1} \mathrm{H}$ NMR spectrum of the polyamide obtained in the polymerization with $p$ nitrobenzoyl chloride in THF at $-40^{\circ} \mathrm{C}$ for $24 \mathrm{~h}$, followed by the end capping reaction with $p$-toluidine. In addition to signals $a-d, h$, and $i$ assignable to polymer backbone, signals $k, i^{\prime}, j$, and $e$ assignable to aromatic and methyl protons of initiating and terminal ends were observed at 7.97, 7.81, 7.52, and $2.32 \mathrm{ppm}$, respectively. The integration ratio of signals between $j$ and $e$ was 2:2.92, which was in good agreement with the 


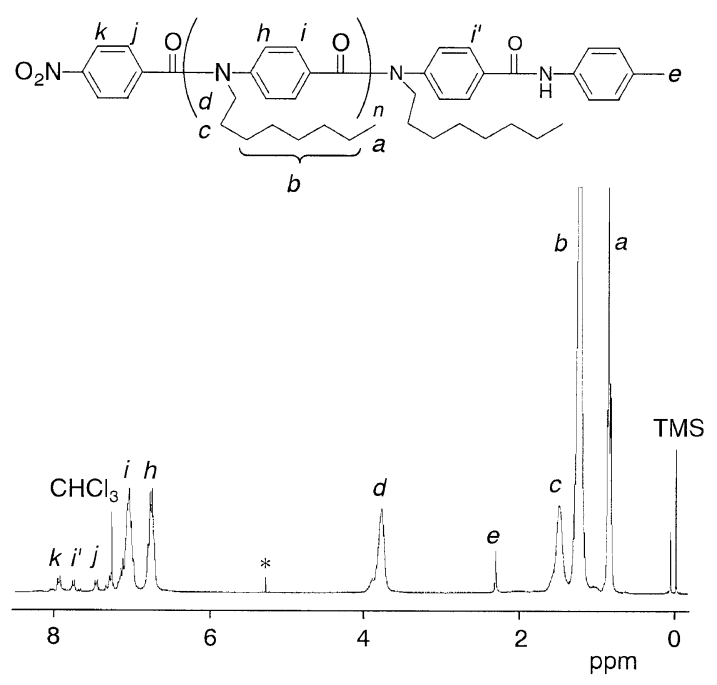

Figure 4. ${ }^{1} \mathrm{H}$ NMR spectrum $\left(300 \mathrm{MHz}, \mathrm{CDCl}_{3}\right)$ of the polyamide obtained in the polymerization with $p$-nitrobenzoic acid chloride in $\mathrm{THF}$ at $-40^{\circ} \mathrm{C}$ for $24 \mathrm{~h}$, followed by the end capping reaction with $p$-toluidine. *is derived from solvent $\left(\mathrm{CH}_{2} \mathrm{Cl}_{2}\right)$.

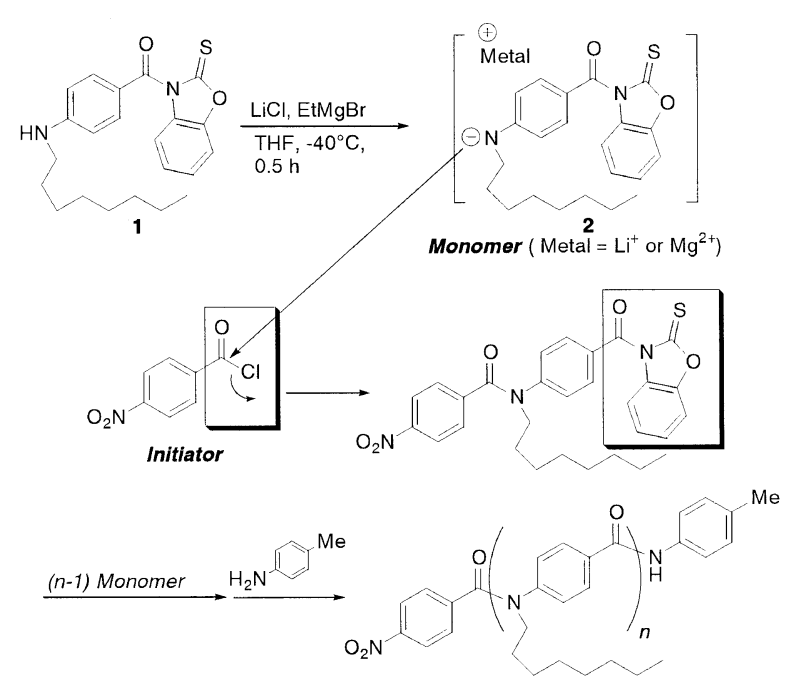

Scheme 6.

theoretical value of 2:3. The $M_{\mathrm{n}}$ calculated from the integration ratio of $j$ and $i$ was 4000 , very close to theoretical one $\left(M_{\mathrm{n}}=3900\right)$ calculated from the feed ratio of the monomer and initiator. These results also supported that the polycondensation in this system proceeds via chain growth manner.

Scheme 6 illustrates a plausible polymerization mechanism in this system. The initiator, $p$-nitrobenzoyl chloride may be attacked by the metal amide of in situ generated monomer $\mathbf{2}$ to afford the neutral amide bond. The reactivity of the resulting active amide against the monomer may be higher than that of the monomer itself whose carbonyl group is inactivated with the strong electron-donating effect of the metal amide. As a result, the monomer may selectively attack on the polymer propagating end (chain growth polymerization mechanism) to give the polymer with controlled $M_{\mathrm{n}}$ and
$M_{\mathrm{w}} / M_{\mathrm{n}}$, whereas the polymerization obey polycondensation mechanism of releasing 2-mercaptobenzoxazole in each step.

\section{SUMMARY}

In this article, we have demonstrated the synthesis of an aromatic polyamide with a narrow $M_{\mathrm{w}} / M_{\mathrm{n}}$ via polycondensation mechanism. New monomer 2 having long alkyl group, active amide, and counter metal cation was designed to prevent conventional polycondensation. The $M_{\mathrm{n}} \mathrm{s}$ of the obtained polymer could be controlled by the amount of $p$-nitrobenzoyl chloride in the range of $10^{3}-10^{4}$ maintaining narrow $M_{\mathrm{w}} / M_{\mathrm{n}} \mathrm{s}$ ( 1.15). The ${ }^{1} \mathrm{H}$ NMR spectroscopic and kinetic studies clearly indicated that the polycondensation in this system proceeded via the chain growth mechanism.

\section{REFERENCES}

1. For example, M. Szwark, Nature, 179, 1168 (1956).

2. a) C. Zune and R. Jérôme, Prog. Polym. Sci., 24, 631 (1999). b) O. W. Webster and B. C. Anderson, "New Methods for Polymer Synthesis", W. J. Mijs, Ed., Plenum Publishing Co., New York, N.Y., 1992, p 1.

3. a) M. Sawamoto, Prog. Polym. Sci., 16, 111 (1991).

b) J. P. Kennedy and B. Iván, "Designed Polymers by Carbocationic Macromolecular Engineering: Theory and Practice", Hanser-Gardner Publications, Munich, 1992.

c) K. Matyjaszewski, "Cationic Polymerizations", Marcel Dekker Inc., New York, N.Y., 1996.

4. K. Matyjaszewski, Ed., "Controlled/Living Radical Polymerization, Progress in ATRP, NMP, and RAFT", ACS Symp. Ser., No. 768, American Chemical Society, New York, N.Y., 2000, p 768.

5. H. Yasuda, Prog. Polym. Sci., 25, 573 (2000).

6. D. Y. Sogah, W. R. Hertler, O. W. Webster, and G. Cohen, Macromolecules, 20, 1473 (1987).

7. R. W. Lenz, C. E. Handlovitis, and H. A. Smith, J. Polym. Sci., 58, 351 (1962).

8. D. R. Robello, A. Ulman, and E. J. Uranaka, Macromolecules, 26, 6718 (1993).

9. a) V. Percec and J. H. Wang, J. Polym. Sci., Part A: Polym. Chem., 29, 63 (1991).

b) V. Percec and J. H. Wang, Polym. Bull., 24, 493 (1990).

10. T. Yokozawa and H. Suzuki, J. Am. Chem. Soc., 121, 11573 (1999).

11. T. Yokozawa, T. Asai, R. Sugi, S. Ishigooka, and S. Hiraoka, J. Am. Chem. Soc., 122, 8313 (2000).

12. T. Yokozawa, Y. Suzuki, and S. Hiraoka, J. Am. Chem. Soc., 123, 9902 (2001).

13. M. Ueda, M. Katayama, T. Morosumi, and R. Sato, Polym. J., 23, 167 (1991).

14. J. D. Albright, V. G. Devries, E. E. Largis, T. G. Miner, M. F. Reich, S. A. Schaffer, R. G. Shepherd, and J. Upeslacis, J. Med. Chem., 26, 1378 (1983). 